\title{
The optimal design of school desks depending on the height and weight of students
}

\author{
Fikret Veljovic $^{1 *}$, Avdo Voloder ${ }^{1}$, Senad Burak ${ }^{1}$, Benjamin Kulovac ${ }^{2}$, Reuf Karabeg ${ }^{3,4}$ \\ ${ }^{1}$ Faculty of Mechanical Engineering, University of Sarajevo, Bosnia \\ ${ }^{2}$ Faculty of Medical Studies, University of Sarajevo, Bosnia \\ ${ }^{3}$ Private Clinic "Karabeg", Bosnia \\ ${ }^{4}$ Faculty of Medical Studies, University of Sarajevo, Bosnia
}

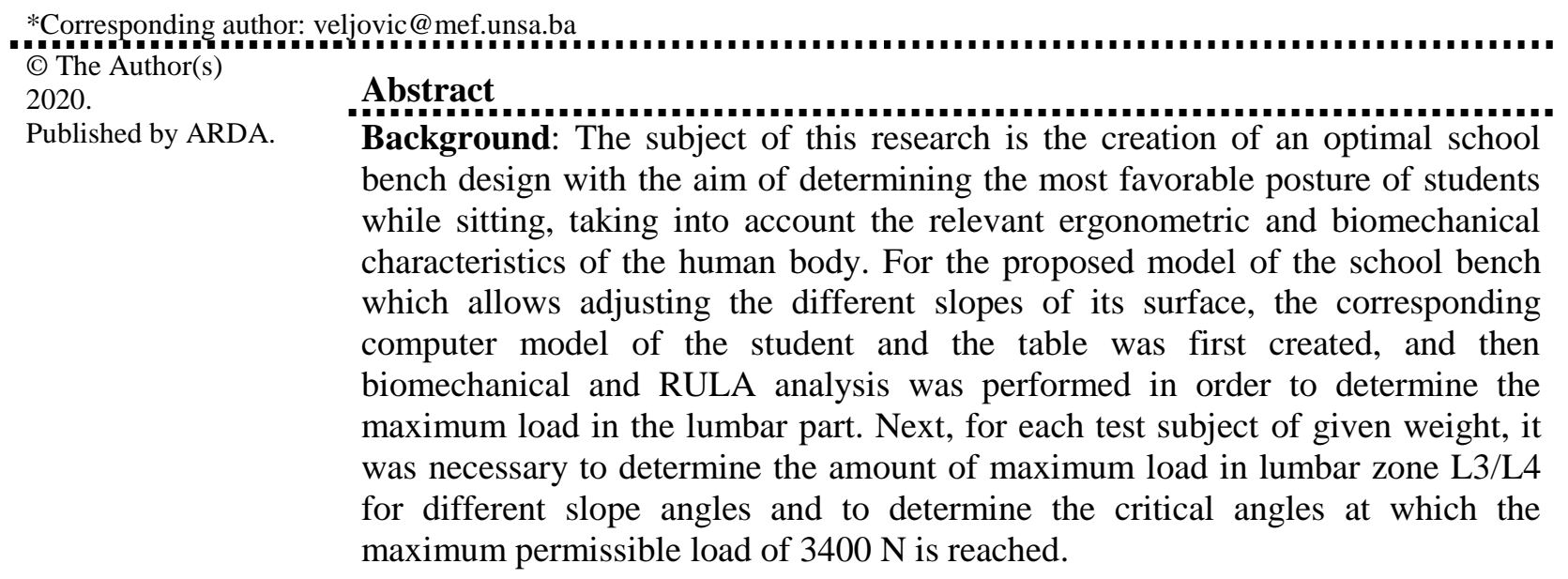

Methods: The analysis is performed on a total of 5 subjects of the same height $(180 \mathrm{~cm})$ and various weights $(60,70,80,90,100 \mathrm{~kg})$. The task is to determine at which weight and at what angle of the workbench with standard height will not exceed the permissible loads of the spine, specifically referring to the L4/L5 vertebrae whose stresses should not exceed $3400 \mathrm{~N}$. The CATIA software package (Dassault Systèmes, Vélizy-Villacoublay, France) is used for the analysis. By knowing the anthropometric and work environment data with ergonomic design and analysis, the following analyzes were made: biomechanical analysis, rapid upper limb assessment (RULA) and carry analysis (an option from CATIA software).

Results: The proposed school bench design allows for flexible adjustments to its worktop, that is, changing its tilt. This allows students of different body masses to have an optimal position at work that does not compromise their maximum permissible load in the L4/L5 spinal column $(3400 \mathrm{~N})$.

Conclusions: The proposed ergonomic design of the desk will result in students being adequately positioned during their activities at school with the minimal risk of permanent deviations and other health problems.

Keywords: Ergonomics, Catia Software Package, Biomechanics, Spinal Column

\section{Introduction}

New approach to the design of the school bench should be based on rational utilization of the working surface as a function of pupils' spinal column loading. It should be taking care of ergonomic principles, optimal consumption of material, furniture price and pedagogical effects [1]. 
It was shown that most of the tables and chairs were not made in accordance with the ergonomic considerations. This results in a number of health problems, especially as Samuel, Joel, Freivalds found that primary school students spend over 30\% of their time at school, mostly sitting at desks [2]. On the other hand, Rungtai Lin and Yen-Yu Kang concluded in their study that the usual school chairs and desks were not consistent with the fact that the classes were not homogeneous in terms of student body weight and that more and more students were overweight [3].

This paper covers an innovative study of the optimal positioning of desktops for students of different body masses using advanced numerical analysis and computer simulations of the CATIA software package (Dassault Systèmes, Vélizy-Villacoublay, France.

\section{Aim}

To present the optimal design of the student's school desk by ergonomic analysis using numerical optimizations and computer simulations and to determine solution for improving working conditions and prevention of musculoskeletal disorders.

\section{Methods}

This research presents an ergonomic analysis performed in the CATIA software package (Dassault Systèmes, Vélizy-Villacoublay, France). The analysis is performed on a total of 5 subjects of the same height $(180 \mathrm{~cm})$ and various weights $(60,70,80,90,100 \mathrm{~kg})$. The task is to determine at which weight and at what angle of the workbench with standard height will not exceed the permissible loads of the spine, specifically referring to the L4/L5 vertebrae whose stresses should not exceed $3400 \mathrm{~N}$

In the work, The RULA Assessment Tool was used to analyze and interpret proposed solution.

\section{Results}

The ideal desk design for students and the values of the optimum slope of its surface for safe student work that does not compromise the permissible maximum spine load of $3400 \mathrm{~N}$ are calculated for different body mass values using the CATIA V5 - R18 software (Dassault Systèmes, Vélizy-Villacoublay, France).

Figure 1 shows a model of the subjects with one of the possible positions with anthropological values, height $\mathrm{h}=180 \mathrm{~cm}$ and mass $\mathrm{m}=70 \mathrm{~kg}$.

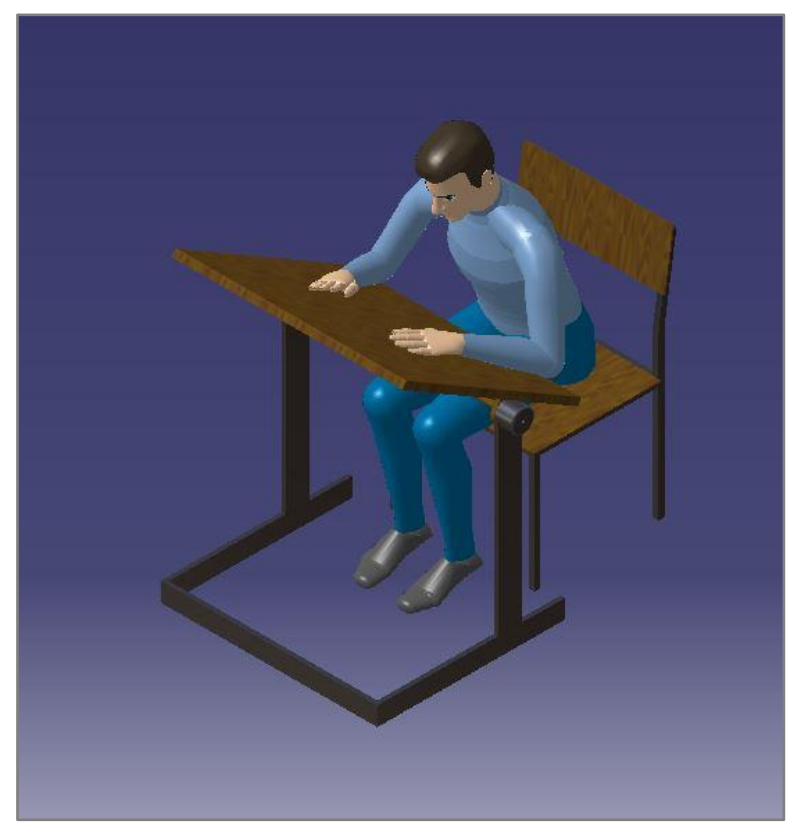

Figure 1. CATIA computer model and typical body position of the student 
Figures 2 and 3 show the results of biomechanical and analysis roll obtained for the subject height $\mathrm{h}=180 \mathrm{~cm}$, mass $\mathrm{m}=70 \mathrm{~kg}$ and the slope of the workbench $\alpha=20^{\circ}$.

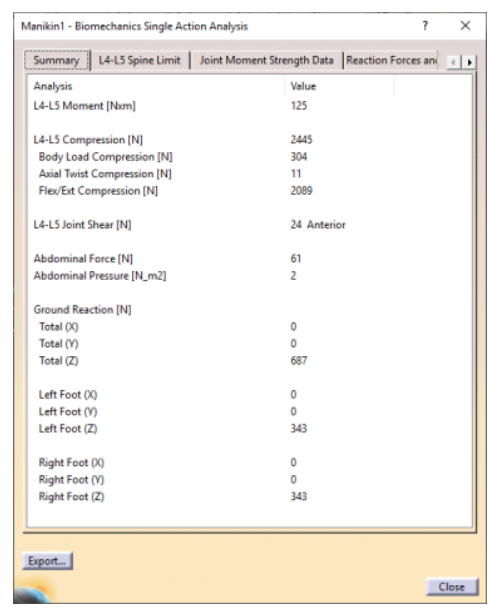

Figure 2. Results of biomechanical analysis for $m=70 \mathrm{~kg}$ and the slope of the workbench $\alpha=20^{\circ}$

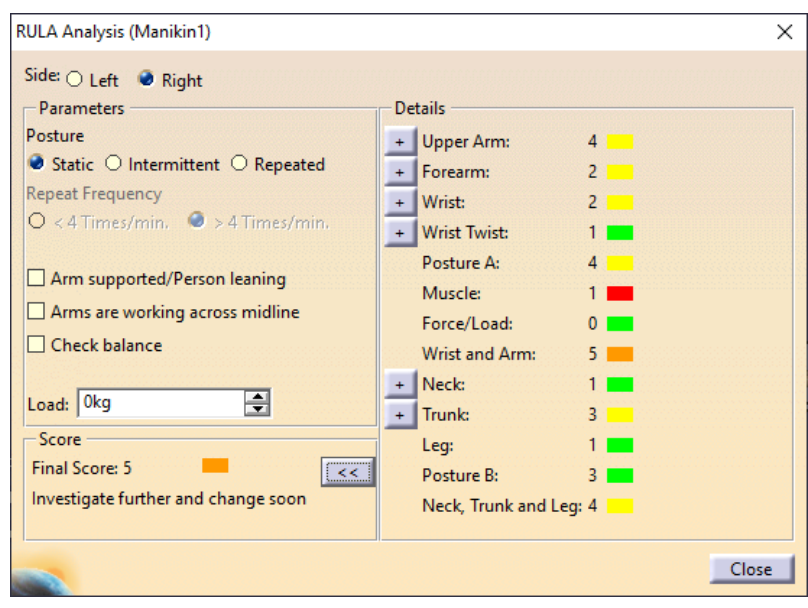

Figure 3. Results of the Rula analysis for the case $m=70 \mathrm{~kg}$ and the slope of the workbench $\alpha=20^{\circ}$

Other results were analyzed and for all possible variants are presented in Table 1.

Table 1. Loads in lumbar L4-L5 vertebrae with biomechanical and RULA analysis

\begin{tabular}{c|c|c|c}
\hline \multirow{3}{*}{$\begin{array}{c}\text { Weight } \\
(\mathrm{kg})\end{array}$} & \multicolumn{2}{|c|}{ Biomechanical analysis } & \multirow{2}{*}{$\begin{array}{c}\text { Rula } \\
\text { analysis } \\
\text { final score }\end{array}$} \\
\cline { 2 - 4 } & $\begin{array}{c}\text { Tilt of the desk } \\
\left({ }^{0}\right)\end{array}$ & $\begin{array}{c}\text { Compression } \\
\text { force (N) }\end{array}$ & 5 \\
\hline \multirow{4}{*}{60} & 0 & 2,473 & 5 \\
\cline { 2 - 4 } & 20 & 2,002 & 5 \\
\cline { 2 - 4 } & 30 & 1,727 & 4 \\
\hline \multirow{4}{*}{70} & 40 & 1,363 & 5 \\
\cline { 2 - 4 } & 0 & 2,884 & 5 \\
\cline { 2 - 4 } & 20 & 2,445 & 5 \\
\hline \multirow{4}{*}{80} & 30 & 2,197 & 5 \\
\cline { 2 - 4 } & 40 & 1,688 & 5 \\
\cline { 2 - 4 } & 0 & 3,294 & 5 \\
\hline \multirow{4}{*}{90} & 20 & 2,789 & 5 \\
\cline { 2 - 4 } & 30 & 2,501 & 5 \\
\cline { 2 - 4 } & 40 & 1,906 & 5 \\
\cline { 2 - 4 } & 20 & 3,703 & 5 \\
\hline \multirow{4}{*}{100} & 30 & 3,429 & 5 \\
\cline { 2 - 4 } & 40 & 2,807 & 5 \\
\cline { 2 - 4 } & 0 & 2,118 & 5 \\
\cline { 2 - 4 } & 20 & 2,813 & 5 \\
\hline
\end{tabular}

As we can see, almost all indicators for 'Final score' have a value of 5, meaning 'Investigate further and change soon' (orange colour). 


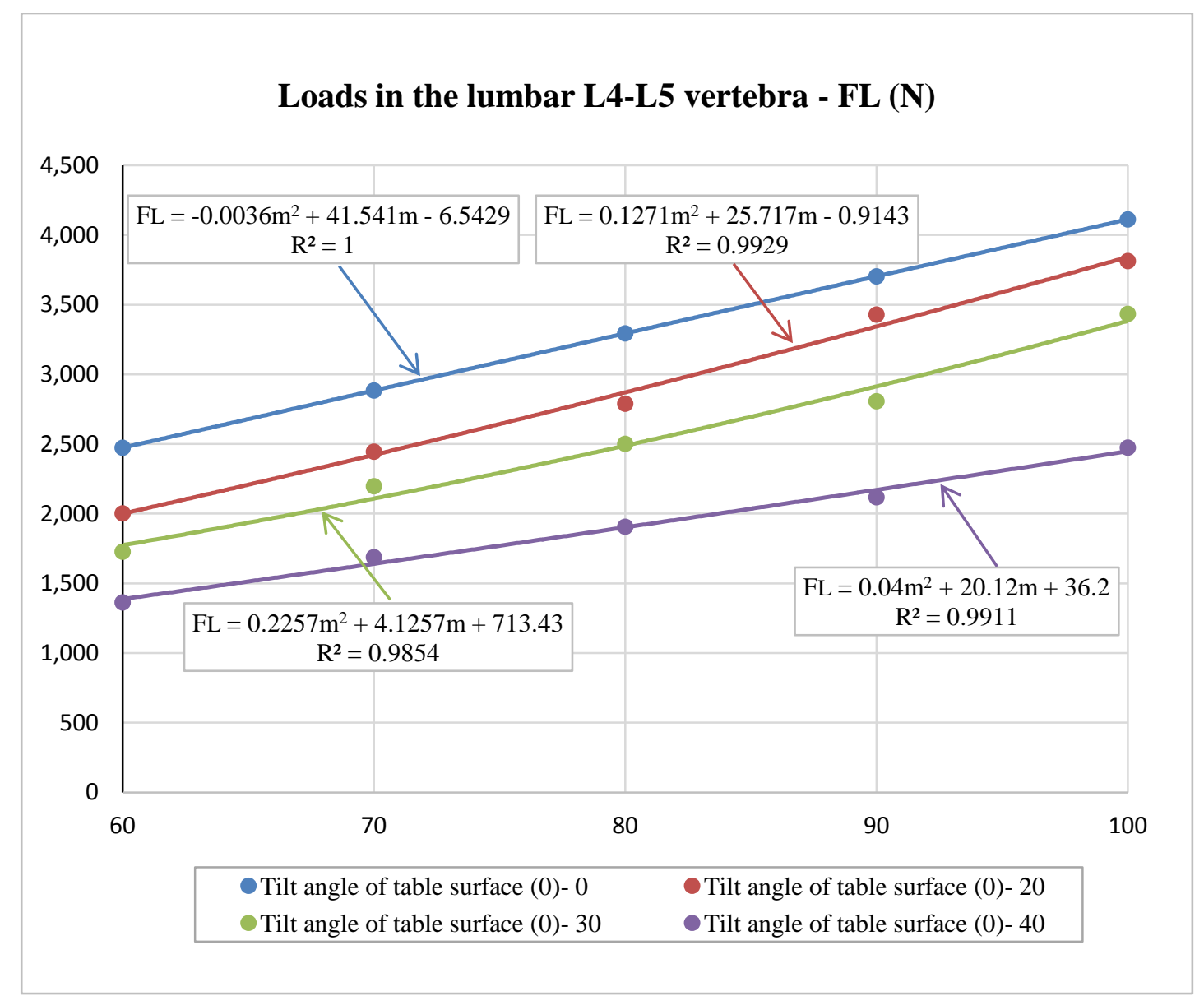

Figure 4. Loads in the lumbar L4-L5 vertebra depending on the mass of the subjects and different angles of inclination of the table surface

For the curve relating to the slope of the workbench of $\alpha=0^{0}$, we find the boundary mass for which the force $F L=3400 \mathrm{~N}$ by the solution of the following equation:

$$
-0.0036 m^{2}+41.541 m-6.5429=3400,
$$

or

$$
-0.0036 \mathrm{~m}^{2}+41.541 \mathrm{~m}-3406.5429=0 .
$$

Solving equation (2) we get that

$$
m_{g r}=82.638 \mathrm{~kg}
$$

meaning that the weight of the subjects for this case must be less than $82.638 \mathrm{~kg}$.

The limit mass for which the force $F L=3400 \mathrm{~N}$ is obtained is similarly obtained for the curve relating to the slope of the desk from $\alpha=20^{\circ}$ :

$$
0.1271 \mathrm{~m}^{2}+25.717 \mathrm{~m}-0.9143=3400
$$

from where we get:

$$
m_{g r}=89.810 \mathrm{~kg}
$$

Solution (5) means that the mass of respondents for this case must be less than $89.810 \mathrm{~kg}$.

For the slope $\alpha=$ od $30^{\circ}$ we get:

$$
m_{g r}=99.960 \mathrm{~kg}
$$

by which we conclude that in this case the weight of the respondents must be less than $99.960 \mathrm{~kg}$. 


\section{Discussion}

The work environment in which students spend most of their time in schools and colleges is most often characterized by work chairs and desks in classrooms [4], [5]. The desk at which students sit and work in the classroom is considered an important element in improving their concentration and overall learning process [6]. An ergonomic analysis of a desk with an optimal design of the position of its surface is therefore considered to be a very important aspect both from the point of view of raising the efficiency of the teaching process and from the point of view of the optimal environment for healthy student development. In doing so, the design of chairs and tables must comply with ergonometric principles as well as the biomechanical characteristics of the human body [7]. We found in our research that persons weighing up to $82.638 \mathrm{~kg}$ can safely work at a desk whose work surface is tilted $0^{0}$, without compromising the permissible spine load of $3400 \mathrm{~N}$. Also, research showed that persons weighing between $82.638 \mathrm{~kg}-89.800 \mathrm{~kg}$ can safely work at a desk whose worktop is inclined $20^{\circ}$ without compromising the permissible spine load of $3400 \mathrm{~N}$. Finally, our study showed that persons weighing between $89.800 \mathrm{~kg}$ and $99.960 \mathrm{~kg}$ can safely work at a desk whose worktop is tilted $30^{\circ}$, without compromising the permissible spine load of $3400 \mathrm{~N}$. The disadvantage of student sitting caused by inadequate chair and bench design results very often in the overload of the student's spinal column, and consequently the resulting skeletal deviations that can result from it [8]. It has been found that more and more problems occur when office workers are sitting in a modern business environment [9]. Daneshmandi et al. state that office workers are in a sitting position for about two-thirds of their working hours, with neck, lower back and shoulder symptoms being the most prevalent problem among workers [10], [11], [12]. The recent study [13] showed the mismatch between university tables and chair dimensions and anthropometric characteristics of students in classrooms.

\section{Conclusion}

Based on the results of the research, appropriate measures can be recommended when planning the procurement of desks in schools and colleges, especially in the situation where student population is increasingly characterized by overweight, including those over a critical size of $82,638 \mathrm{~kg}$.

The proposed ergonomic design of the desk will result in students being adequately positioned during their activities at school with the minimal risk of permanent deviations and other health problems. Considering the above analysis, it would be advisable to introduce the possibility of correcting student desks in classrooms and amphitheaters in accordance with their anthropometric values.

\section{References}

[1] F. Veljovic, M. Petrovic. "Optimal Utilization of the School Bench with Regard to the Spinal Column Loading of Pupils in Sitting Position", TEM Journal, Volume 8, Issue 2, 396-401, 2019.

[2] S. Oyewolea, J. Haightb, A. Freivalds, "The ergonomic design of classroom furniture/computer work station for first graders in the elementary school", International Journal of Industrial Ergonomics, Vol. 40. Issue 4, 437-447, 2010.

[3] L. Runtgai, Y. Kang, "Ergonomic Design of Desk and Chair for Primary School Students in Taiwan", International Journal of Innovation, Management and Technology, 4(1), 1-6, 2013.

[4] M. Meeks, T. Knotts, K. James, F. Williams, J. Vassar, A. Oakes Wren, "The Impact of Seating Location and Seating Type on Student Performance", Educ. Sci., 3, 375-386, 2013.

[5] S. Burak, F. Veljovic, "Ergonomic Analysis and Redesign of Workspace in Order to Minimize Workers' Workload and Optimize Their Nutrition", TEM journal, 8(2): 572-76, 2019.

[6] Allegri M, Montella S, Salici F, Valente A, Marchesini M, Compagnone C, et al. "Mechanisms of low back pain: a guide for diagnosis and therapy", Version 2. F1000Res. 2016.

[7] J. Salmon, N. Owen, D. Crawford, A. Bauman, J. Sallis, "Physical activity and sedentary behavior: a population-based study of barriers, enjoyment, and preference", Health Psychol. 22(2):178-88, 2003.

[8] N. Al-Hinai, M. Al-Kindi, A. Shamsuzzoha, "An Ergonomic Student Chair Design and Engineering for Classroom Environment", International Journal of Mechanical Engineering and Robotics Research Vol. 7, No. 5, 2018. 
[9] T. Church, D. Thomas, C. Tudor-Locke, P. Katzmarzyk, C. Earnest, R. Rodarte, C. Martin, S. Blair, C. Bouchard, "Trends over 5 decades in US occupation-related physical activity and their associations with obesity", PLoS One., 6: e19657, 2011.

[10] H. Daneshmandi, A. Choobineh, H. Ghaem, M. Karimi, "Adverse effects of prolonged sitting behavior on the general health of office workers", J Lifestyle Med., 7, 69-75, 2017.

[11] S. Gajghate, Goilkar, S. Jagtap, C. Deokate, "A Review of Design and Development of College Bench by Ergonomics \& Anthropometry Concept", IEEE International Conference on Emerging Trends in Engineering, Technology and Science ICETETS, Volume: 978-1-4673-6725-7, 2016.

[12] C. Nelofer Khanam, M. Reddy, A. Mrunalini, "Designing Student's Seating Furniture for Classroom Environment", J. Hum. Ecol., 20(4): 241-248, 2006.

[13] T. Kumar, R. Mustafizur, M. A. Zaman, M. Uddin, "Ergonomic Design of Table and Chair based on QFD and Anthropometric Measurement and improved Facility Layout", Ergonomics International Journal, Vol 2. Issue 3. 2018. 